\title{
Burkholderia cepacia: medical, taxonomic and ecological issues
}

\author{
J. R. W. GOVAN, JAYNE E. HUGHES and P. VANDAMME*
}

Department of Medical Microbiology, University of Edinburgh Medical School, Teviot Place, Edinburgh EH8 $9 A G$ and * Laboratorium voor Microbiologie, Universiteit Gent, KL Ledeganckstraat 35, B-9000 Gent, Belgium

\begin{abstract}
The increasing challenge posed by multiresistant saprophytes in medical microbiology is strikingly demonstrated by the emergence of Burkholderia (formerly Pseudomonas) cepacia as an opportunist pathogen in immunocompromised patients, particularly individuals with chronic granulomatous disease and cystic fibrosis (CF). Best known previously as a phytopathogen and the cause of soft rot of onions, B. cepacia presents three major problems for the CF community: innate multiresistance to antimicrobial agents; person-to-person transmission of epidemic strains through nosocomial or social contacts; and 'cepacia syndrome', a fulminating fatal pneumonia, sometimes associated with septicaemia, that occurs in approximately $20 \%$ of colonised patients, including those with previously mild disease. Accumulated evidence to dispel earlier suggestions that the organism is avirulent and merely a marker of existing lung disease includes: case-controlled studies in CF patients; reports of serious infections in non-CF patients; in-vitro and in-vivo evidence that $B$. cepacia induces production of pro-inflammatory markers, including the major cytokine TNF $\alpha$; and histopathological evidence that exposure of transgenic CF mice to $B$. cepacia results in pneumonia. By the early 1990s, the use of selective culture media and DNA-based bacterial fingerprinting confirmed suspicions of epidemic person-to-person spread of $B$. cepacia. This evidence provided scientific justification for draconian and controversial measures for infection control, in particular, segregation of $B$. cepacia-colonised patients during treatment at $\mathrm{CF}$ centres and their exclusion from social gatherings and national conferences. Recently, molecular analyses of type strains and clinical isolates have revealed that isolates identified previously as $B$. cepacia belong to at least three distinct species and have increased concern regarding the reliability of current laboratory detection and identification systems. Clarification of the taxonomy of $B$. cepacia-like organisms and the pathogenic potential of environmental isolates remains a high priority, particularly when the organism's antifungal and degradative properties have created interest in its potential use as a biological control agent to improve crop yields and its use for the bioremediation of contaminated soils.
\end{abstract}

\section{Introduction}

'The development of multiresistance in major microbial pathogens is well-recognised; in contrast, little attention has been paid to the pathogenic potential of naturally resistant environmental saprophytes'.

Known originally as a phytopathogen, Burkholderia cepacia (previously Pseudomonas cepacia, P. multi-

Received 10 June 1996; accepted 19 June 1996.

Corresponding author: Dr J. W. R. Govan. vorans, $P$. kingii, 'Eugonic oxidiser 1') exhibits impressive nutritional versatility. Some microbes have an inherent or acquired ability to degrade antibiotics, but few have the ability to use penicillin as a sole carbon source [1] or to reduce onions to a macerated pulp! The earlier name, $P$. multivorans, reflected the organism's omnivorous appetite, but it was not until 1950 that its pathogenic potential was recognised when Burkholder identified the organism as the cause of soft rot of onions-particularly 'compromised' onions damaged during harvesting-and provided an appropriate species epithet (Latin: cepia = onion) [2]. In the early 1990s, following taxonomic re-appraisal, the RNA group II pseudomonads were recognised as 
the new genus Burkholderia, with B. cepacia as the type species [3]. At present, the genus Burkholderia comprises B. cepacia, B. gladioli, B. mallei, $B$. pseudomallei, $B$. caryophylli, and recently added to the group, B. plantarii, B. glumae, B. vandii [4], $B$. cocovenenans [5] and B. vietnamiensis [6].

The general characteristics of $B$. cepacia include the following: gram-negative, non-spore-forming, aerobic bacillus; motile with a respiratory metabolism and typically catalase- and oxidase-positive; various nonfluorescent pigments may be produced and poly- $\beta$ hydroxyalkanoates can be accumulated as reserve materials; the optimal temperature for growth is $30-$ $35^{\circ} \mathrm{C}$ [7]. Recently, elegant molecular analyses have provided scientific evidence that may account for the organism's impressive versatility, including multilocus linkage disequilibrium analysis of environmental populations [8] - which suggested an extraordinarily high rate of recombination in $B$. cepacia relative to binary fission - and demonstration of multiple replicons and insertion sequences in type strains $[9,10]$.

The natural habitats of $B$. cepacia have been described as soil, water and vegetation [11]. However, it is a common but erroneous belief that $B$. cepacia is a ubiquitous saprophyte sharing similar environmental habitats with Pseudomonas aeruginosa and other pseudomonads. Extensive surveillance studies have shown that culture of $B$. cepacia from natural sources, including soil, water and plants, or from hospitals, foodstores, restaurant salad bars and patients' homes is surprisingly difficult, with detection rates of only $1-$ $16 \%[12-16]$.

In agricultural microbiology, ecological awareness and an increasing incidence of pesticide-resistant pathogens have led to interest in B. cepacia as a potential agent for biological control and soil decontamination. $B$. cepacia produces several antimicrobial agents, including pyrrolnitrins, altericidins, cepalycins and bacteriocin-like agents [17-20], that inhibit bacterial and fungal phytopathogens and suppress tobacco wilt and other plant diseases [21]. B. cepacia is also capable of degrading industrial waste and herbicides, including 2,4,5-trichlorophenoxyacetic acid (2,4,5-T), the principal ingredient of the highly potent 'agent orange' [22]. Indeed, B. cepacia has been shown to degrade $2,4,5-\mathrm{T}$ in heavily contaminated soils at a rate up to 20000 -fold greater than other known degradative bacteria [23].

In contrast to its potential agricultural benefits, $B$. cepacia has also emerged as a multiresistant opportunist human pathogen, leading to concern about the relationship between environmental and clinical isolates $[14,24-26]$ and the potential hazards of releasing $B$. cepacia as a biological control agent [14,24]. This review will provide an update on microbes currently described as $B$. cepacia, with particular focus on clinical, taxonomic and ecological issues (Table 1) associated with pulmonary infection in patients with cystic fibrosis (CF).

\section{The emergence of $\boldsymbol{B}$. cepacia as a human pathogen}

Before the early 1980s, reports of human infections caused by $B$. cepacia were sporadic and generally restricted to hospitalised patients exposed to contaminated disinfectant and anaesthetic solutions in which this nutritionally adaptable saprophyte survives for long periods. Infections included those of soft tissues and the respiratory and urinary tracts, but bacteraemia also occurred, sometimes associated with endocarditis and septic shock [27-31]. A rising incidence of B. cepacia infection was noted during the early $1980 \mathrm{~s}$ and, although in some cases culture of B. cepacia was thought to reflect mere colonisation or contamination rather than infection $[11,32]$, extensive analyses of USA databases of nosocomial infections confirmed a significant increase in clinically significant $B$. cepacia infections $[33,34]$. The apparent propensity of $B$. cepacia to cause fatal pulmonary infections, as suggested by these analyses, is emphasised in patients with chronic granulomatous disease (CGD) - in whom $B$. cepacia pneumonia and septicaemia are lifethreatening $[35,36]$ - and in its emergence as a major pathogen in patients with CF [37-39]. By the 1990s, disturbing reports also emerged of fatal cases of $B$. cepacia pneumonia and septicaemia in previously

Table 1. Major issues associated with B. cepacia and cystic fibrosis (CF)

- Is there convincing evidence to confirm that $B$. cepacia has pathogenic potential and is not merely a marker of pulmonary disease?

- Based on the success, but unpopularity, of segregation and advances in clarifying the taxonomy of the genus Burkholderia, should all B. cepacia be treated as equal? Can phenotypic or genomic markers be found which would identify highly transmissible or virulent clones?

- To what degree do natural environments represent a reservoir for B. cepacia and a hazard for CF patients? What hazards are associated with the development and use of $B$. cepacia as a biological control agent?

- Could an improved understanding of the host immune response, including enhanced cytokine induction by bacterial surface components, clarify the immunopathology of $B$. cepacia and lead to innovative forms of immunotherapy?

- At present, it is not possible to forecast the clinical outcome of $\mathrm{B}$. cepacia colonisation. Can host and bacterial factors responsible for initial colonisation and poor clinical outcome be identified?

- Recently, it has been demonstrated that CF airway epithelia contain bactericidal activity that is inhibited reversibly by high NaCl concentrations. Does this killing potential include B. cepacia and is it host or strain specific?

- Ultimately, the identification of bacterial and host factors associated with transmission and virulence would assist greatly in the rational design of an effective $B$. cepacia vaccine. 
healthy individuals $[40,41]$. Community-acquired $B$. cepacia infections are uncommon, but the organism's pathogenic potential and the financial implications of antimicrobial therapy were recently strikingly demonstrated when an offshore oil worker developed multiple brain abscesses secondary to suppurative otitis media. Therapy involved four neurosurgical operations, an extensive period of hospitalisation and an antibiotic bill of $£ 10 \mathrm{~K}[42]$.

The above case also demonstrated an interesting and unexplained variability in antibiotic susceptibility profiles that has been observed in serial $B$. cepacia isolates from single patięnts and during epidemic outbreaks [43-46]. The mechanism responsible for variable susceptibility is unclear, but may be associated with the observation that migration of insertion sequences within the $B$. cepacia genome can affect the expression of genes that modulate antibiotic resistance [47].

\section{B. cepacia and cystic fibrosis}

During the last decade, the major clinical interest in $B$. cepacia has focused on its addition to the relatively narrow spectrum of microbial pathogens responsible for debilitating and ultimately fatal pulmonary infections in patients with CF $[26,39,48,49]$. In the late 1980 s, surveillance studies in the UK indicated a maximum prevalence of $7 \%[39,50-52]$; however, in some CF centres this later increased to approach the prevalence of $40 \%$ described in contemporary North American studies [53]. The three major issues concerning $B$. cepacia can be summarised as follows: 1 , the clinical risk of rapid and fatal pulmonary decline, even in patients with previously mild disease; 2 , patient-topatient spread of epidemic strains within and between regional CF centres and between centres in the UK and North America; and 3, the innate multiresistance of most B. cepacia isolates to available antibioticswhich deprives patients of effective antimicrobial therapy $[46,54]$ - combined with the failure to reduce the bacterial population in sputum and a relatively poor clinical response even when the colonising strain exhibits in-vitro susceptibility.

The clinical significance of B. cepacia in CF patients was first described in 1984 in a seminal report by Isles et al. [37]. In addition to noting the increased prevalence of $B$. cepacia colonisation in patients attending Toronto clinics, Isles et al. described a rapid and unexpected clinical decline, including necrotising pneumonia and bacteraemia, that occurred in c. $20 \%$ of colonised patients. This acute clinical decline is sometimes referred to as "cepacia syndrome' [37]. It is important to note that acute clinical deterioration and bacterial spread to sites other than the lung is not observed with the other major $\mathrm{CF}$ pathogens, Staphylococcus aureus, Haemophilus influenzae and P. aeruginosa.
The second major issue relating to $B$. cepacia arose in the mid $1980 \mathrm{~s}$ as an increasing-but scientifically unproven - conviction held by some $\mathrm{CF}$ carers that the clustering of cases in some large North American clinics had arisen from cross-infection. At that time, an alternative explanation for clustering was the difficulty in culturing this relatively new pathogen from CF sputa [48]. As evidence, in a controlled study involving 115 North American CF centres, only 36 (31\%) cultured the organism successfully from a seeded sputum specimen [55]. However, by the early 1990 s, the availability of selective culture media [48] and awareness of the organism's cultural idiosyncrasies [56] indicated that regional variation in the prevalence of B. cepacia colonisation could not be explained simply by laboratory methodology. Furthermore, the development and use of bacterial fingerprinting techniques-including multilocus enzyme electrophoresis (MLEE), pyrolysis mass spectroscopy, PCRribotyping and pulsed-field gel electrophoresis (PFGE)-provided compelling evidence for personto-person spread of B. cepacia through nosocomial and social contacts (Table 2) $[25,37,46,57-75]$ and, occasionally, in the absence of proven sputum colonisation [67]. Epidemiological data also provided scientific justification for the introduction of guidelines by national $\mathrm{CF}$ organisations to improve personal and hospital hygiene and, more controversially, for the implementation of segregation policies to limit contact between colonised and non-colonised individuals [76]. Surveillance studies show that segregation undoubtedly reduces the incidence of $B$. cepacia cross-infection $[38,62,71,77]$, but the strategy has not eliminated acquisition. Furthermore, the logistic and social consequences of draconian infection control measures reminiscent of mediaeval approaches to leprosy have not been accepted universally. In particular, the need for such measures has been questioned fiercely by patients and care-givers in CF centres where intensive surveillance has not revealed a high incidence or prevalence of $B$. cepacia colonisation.

\section{A pathogen or a marker of lung disease?}

In the 1970s, some microbiologists and clinicians considered $S$. aureus to be the only true microbial pathogen in CF patients and viewed $P$. aeruginosa as merely a marker of disease. A similar doubt has accompanied the emergence of B. cepacia and has exacerbated the controversy surrounding segregation of colonised individuals. In discussions of any potential opportunist pathogen, it is easy to find evidence of asymptomatic carriage; even Salmonella typhi and Vibrio cholerae do not invariably exhibit pathogenicity!

Clarification of the clinical relevance of B. cepacia is also thwarted by the fact that the available scientific evidence requires particularly careful analysis. There is an inclination to link bacterial transmissibility and virulence, and to categorise individual $B$. cepacia 
Table 2. Evidence for and against person-to-person transmission of B. cepacia

\begin{tabular}{|c|c|}
\hline Reference & Comments \\
\hline \multicolumn{2}{|c|}{ A. Evidence in favour of person-to-person transmission } \\
\hline Isles et al. [37] & Seminal paper: noted rising incidence of $B$. cepacia and cepacia syndrome in Canadian clinics \\
\hline Thomassen et al. [57] & Fall in incidence after segregation \\
\hline LiPuma et al. [58] & Prevalence of one ribotype in individual clinics \\
\hline LiPuma et al. [59] & Ribotyping demonstrates person-to-person spread between two patients at a $\mathrm{CF}$ camp \\
\hline Anderson et al. $[60]$ & Nosocomial outbreak \\
\hline Millar-Jones et al. [61] & UK nosocomial outbreak \\
\hline Govan et al. [62] & $\begin{array}{l}\text { Genotypic fingerprinting and extensive epidemiological data provides compelling evidence of } \\
\text { person-to-person spread through social contact in and between two UK CF centres }\end{array}$ \\
\hline Smith et al. [63] & Further UK outbreak with transmission in clinical and social settings \\
\hline Bingen et al. [64] & International consensus confirming $B$. cepacia transmissibility \\
\hline Corkill et al. [65] & Highlights transmission particularly at UK CF events \\
\hline Pegues et al. [66] & Demonstration of transmission at USA CF camps \\
\hline Johnson et al. [25] & Intercontinental spread of Edinburgh/Toronto strain ET12 \\
\hline LiPuma et al. [67] & Inapparent transmission from culture-negative patient (?) \\
\hline Ryley et al. [68] & Further UK outbreak \\
\hline Sun et al. [69] & Cable pili demonstrated on intercontinental strain (ET12) \\
\hline Revets et al. [70] & Prevalent strain in Belgian clinic \\
\hline Whiteford et al. [71] & Outbreak in UK paediatric clinic \\
\hline Pitt et al. [46] & Strain ET 12 prevalent in UK clinics: accounting for $38 \%$ of cases \\
\hline \multicolumn{2}{|c|}{ B. Cases with no evidence of person-to-person transmission } \\
\hline Glass and Govan [72] & No transmission of pathogenic strain between siblings \\
\hline Hardy et al. [73] & No transmission to uncolonised patients during hospitalisation \\
\hline Taylor et al. [74] & No transmission in UK unit before segregation \\
\hline Steinbach et al. [75] & No transmission in large $\mathrm{CF}$ unit despite no segregation of hospitalised patients \\
\hline
\end{tabular}

strains as either transmissible and virulent, or nontransmissible and avirulent. There is no scientific justification for this view. In epidemic outbreaks in which patients are colonised by the same strain, some patients may remain asymptomatic whilst other individuals succumb to rapid and unexpected fatal deterioration [37,62]. In the case of transmission, epidemiological evidence has clearly identified lineages with enhanced transmissibility $[25,46,62$, 69]; however, based on present knowledge, it cannot be stated with confidence that a strain inherently lacks the ability for epidemic spread. Furthermore, apparently 'non-transmissible' strains that have not spread even to a patient's CF sibling have been responsible for fatal infection [72]. Finally, it could be argued that transmission is not strain-dependent, but is associated with nosocomial or social opportunities for transmission. This hypothesis is certainly not supported by the behaviour of the particular B. cepacia lineage with a notorious ability to spread in CF centres in the UK $[46,62]$ and North America [25, 69], referred to as the Edinburgh/Toronto lineage [69] or ET12 intercontinental clone (multilocus enzyme electrophoresis type 12) [25]. For convenience, this particular B. cepacia lineage will be referred to as the ET12 lineage in the remainder of this review.

Some CF carers who have experienced transmission of $B$. cepacia amongst small numbers of their patients have argued against segregation on the grounds that no significant clinical deterioration was observed and that implementation of such draconian measures stigmatises patients and prevents valuable social contacts with other CF patients [70]. However, the hypothesis that $B$. cepacia is transmissible but merely a marker of pulmonary deterioration can be chal- lenged. A recent retrospective study of the clinical status of B. cepacia-colonised adults in the 24-month period before colonisation found no difference in their lung function, number of days in hospital or outpatient visits [77]. Furthermore, in numerous case-controlled studies involving large numbers of patients, B. cepacia colonisation has been associated in some but not all patients with an accelerated decline in pulmonary function and a poor prognosis [71,77-81]. Most studies have reported that the risk of clinical deterioration on acquisition of $B$. cepacia is increased in adult patients with severe disease [78-80]. This contrasts with an epidemic outbreak of $B$. cepacia among children, in whom the dominant impact on respiratory function was greater in patients with better levels of respiratory function [71]. Explanations for the range of clinical responses associated with $B$. cepacia colonisation and inability to predict the clinical outcome in individual patients could include: 1 , differences in strain virulence; 2 , the relatively low $20 \%$ 'strike rate' of cepacia syndrome; 3 , the influence of co-colonisation by other pathogens; 4 , the age at which colonisation occurs; 5, individual host immune responses; and 6 , the severity of underlying CF disease.

The hypothesis that $B$. cepacia colonisation is merely a marker of severe lung disease is also undermined by the fact that fatalities have occurred in CF adults with mild $\mathrm{CF}$ disease, including individuals not already harbouring $P$. aeruginosa [62]. Finally, one of the most striking results from the first microbiological studies in transgenic $\mathrm{CF}$ mice showed that $70 \%$ of $\mathrm{CF}$ mice exposed to $B$. cepacia succumbed to more severe broncho-pulmonary infection than control animals [82]. 


\section{The Edinburgh/Toronto/ET12 epidemic lineage}

In reviewing the emergence of $B$. cepacia in $\mathrm{CF}$ populations in Europe and North America, it is necessary to emphasise the influence of epidemic lineages on the incidence and prevalence of $B$. cepacia within $\mathrm{CF}$ centres. Evidence shows that the incidence in a centre can be influenced greatly by the epidemic spread of a single lineage, and that if such spread is discounted then the prevalence of B. cepacia in most $\mathrm{CF}$ centres remains relatively low at $5-10 \%$. Transient colonisation by $B$. cepacia also influences prevalence and occurs in c. $5 \%$ of $\mathrm{CF}$ patients; however, transient colonisation is observed very rarely with the ET12 lineage (authors' unpublished observations), perhaps reflecting the high colonisation potential of this clone. From a clinical, epidemiological and evolutionary viewpoint, the influence of this single clone on the CF community is considerable. In the UK alone, it has been isolated in eight $(50 \%)$ of $16 \mathrm{CF}$ centres and from $68(38 \%)$ of 178 B. cepacia-colonised patients [46]. Attempts to identify its origins have been frustrated by a lack of stored isolates; however, investigation of available isolates allows several conclusions to be reached. Based on evidence from MLEE and ribotyping [25] and PFGE [46, 62], the first known isolates of this epidemic lineage were cultured from Ontario paediatric patients in the latter half of the 1980s [25]. In the UK, the first recorded isolate of the same lineage was in August 1989 [62] from a patient who had never been out of the UK nor shown any evidence of $B$. cepacia colonisation during previous bacteriological investigations. The patient had previous contacts with other UK patients colonised by $B$. cepacia, but the isolates from these patients were not available.

From the available evidence, it appears that the Edinburgh/Toronto/ET12 lineage was established in Canada before its appearance in the UK, and that at some stage in the late $1980 \mathrm{~s}$, intercontinental spread occurred between UK and Canadian patients whilst attending summer camps in Ontario, followed by interregional spread in the UK during social contacts at meetings $[25,62]$. It is tempting to conclude that this highly transmissible strain is clonally related to the isolates cultured during the first documented outbreak of B. cepacia in CF patients in Ontario, reported in 1984 [37].

\section{Potential pathogenic mechanisms of $B$. cepacia}

Although B. cepacia produces several putative virulence determinants - including haemolysins, proteases, lipases, siderophores and catalase-a major clinical role for these factors has not been demonstrated convincingly in $\mathrm{CF}[83,84]$. However, catalase is associated with the organism's ability to resist killing by professional phagocytes and to produce serious infection in patients with CGD [85].

\section{Intracellular survival}

Several puzzling clinical and scientific observations have led to speculation that $B$. cepacia can survive and grow within pulmonary phagocytes or respiratory epithelial cells. First, clinical resistance to antimicrobial therapy despite demonstration of an isolate's susceptibility in vitro; second, isolation of serumsensitive isolates in bacteraemic infection [86]; third, chronic pulmonary colonisation despite a pronounced antibody response [87]; and fourth, the close taxonomic relationship between $B$. cepacia and the intracellular pathogen, B. pseudomallei. However, to date, the scientific evidence for intracellular survival or growth of B. cepacia is not convincing. Studies of intracellularity in bacterial pathogens can be difficult and, in the case of B. cepacia, are complicated further by the organism's innate resistance to antibiotics, including aminoglycosides, which are used commonly in intracellular assays to kill extracellular organisms. As it is known that $B$. pseudomallei survives and multiplies within professional phagocytes [88], studies within our group have focused on monocytes, with Listeria monocytogenes and $P$. aeruginosa as positive and negative controls, respectively. However, it was not possible to demonstrate either enhanced uptake or survival of $B$. cepacia in monocytes. Previously, Burns [89] reported the observation of $B$. cepacia within CF post-mortem respiratory epithelial cells by electron microscopy, but no further data have been published to validate this important finding. Low-level invasion in vitro of a respiratory epithelial cell line by the epidemic ET12 lineage has been demonstrated [90], but the significance of limited epithelial invasion by bacteria remains unclear [91]. A recent and potentially seminal publication has even suggested that enhanced uptake of CF pathogens by epithelial cells expressing surface cystic fibrosis transmembrane conductance regulator (CFTR), followed by epithelial desquamation, may be an important host defence mechanism rather than a bacterial virulence determinant [92].

Overall, the role of intracellularity in the pathogenesis of $B$. cepacia infection in CF patients is still in doubt. As a caveat, the demonstration of its intracellular survival and growth within amoebae, raises the possibility that these free-living protozoa may act as an environmental reservoir from which $\mathrm{CF}$ patients could acquire the organism [93].

\section{B. cepacia and host immune responses}

Colonisation with $B$. cepacia is associated with a pronounced and specific humoral response, including raised serum $\operatorname{IgG}$ and $\operatorname{IgA}$ and sputum $\operatorname{IgA}$ titres against $B$. cepacia lipopolysaccharide (LPS) and outermembrane protein (OMP) components [87, 94]. Anti- $B$. cepacia antibodies have also been detected in noncolonised CF patients, and particularly in patients colonised with $P$. aeruginosa $[87,95]$. Studies with preabsorbed sera have failed to demonstrate an appreciable 
degree of cross-reactivity between the two species, either for OMP or LPS components [87, 96], suggesting that the response to $P$. aeruginosa is not the source of pre-colonisation anti- $B$. cepacia antibody. Generally, levels of anti-B. cepacia immunoglobulin in noncolonised patients are low, but the demonstration of substantially raised titres in a subset of patients may reflect previous exposure to $B$. cepacia where an appropriate antibody response has prevented the occurrence of colonisation. On the other hand, the demonstration of antibody in stored pre-colonisation sera from patients who subsequently became colonised, indicates that antibody does not always play a preventative role. Similarly, the role of antibody in patients once they are colonised is unclear; for example, clinical outcome is independent of the magnitude of anti- $B$. cepacia responses [87]. A recent study [97] with immunoblotting techniques has suggested that IgG antibodies against a $30-\mathrm{kDa}$ OMP, identified presumptively as the major immunodominant porin, OMP D $[95,98]$, are associated with a better prognosis in colonised patients. If these results are confirmed, it raises the possibility of using this OMP as a target for immunotherapy.

The association of B. cepacia with CGD, an inherited defect in neutrophil oxidative killing pathways, and the role of neutrophils as the predominant immune effector cell in the CF lung [99], have led to speculation that the interaction between $B$. cepacia and neutrophils may be important in the evasion of host defences by this organism. Speert et al. [85] demonstrated that, unlike $P$. aeruginosa, B. cepacia is resistant to non-oxidative neutrophil killing mechanisms; hence the role of B. cepacia in CGD. Evasion of the normal neutrophil oxidative burst would aid the survival of B. cepacia in the presence of a pronounced immune response. Within the CF lung, normal opsonisation processes are compromised severely through the disruption of immune effector molecules by bacterial and host proteases $[100,101]$. In particular, cleavage of complement receptors and immunoglobulin molecules within the respiratory tract may neutralise the humoral immune response to $B$. cepacia and enable the organism to persist in the lungs of colonised patients. However, this observation does not explain the ability of rough, LPS-deficient, serumsensitive $B$. cepacia to cause invasive pneumonitis and septicaemia in patients with elevated anti- $B$. cepacia immunoglobulin titres [86].

\section{Inflammatory damage}

Increasing evidence has emerged to suggest that host immune responses are important in the pathogenesis of B. cepacia infection. A UK multicentre study has shown that levels of the inflammatory markers, Creactive protein and neutrophil elastase $\alpha 1$-antiproteinase complex, are significantly higher during $B$. cepacia-associated exacerbations than in exacerbations caused by $P$ aeruginosa alone. Aggressive antibiotic treatment with the most active agents available did not eliminate $B$. cepacia, but in most cases was associated with a decline in inflammatory markers to preexacerbation levels [102]. In addition, anecdotal evidence indicates that patients who exhibit rapid pulmonary decline and pronounced inflammatory symptoms, but who do not respond to antibiotic therapy, nevertheless respond to treatment with commercial preparations of immunoglobulin. The relative absence of $B$. cepacia antibodies in healthy human donors [87], from whom these immunoglobulins are obtained, suggests that such preparations contain potentially useful anti-inflammatory activity.

An unexpected but informative result from our own studies has demonstrated that LPS from clinical and environmental isolates of $B$. cepacia induces proinflammatory cytokines, including the major cytokine tumour necrosis factor $\alpha$ (TNF $\alpha)$, to a level 10-fold that induced by $P$. aeruginosa LPS and matching the inflammatory power of Escherichia coli endotoxin $[103,104]$. The mechanism involved in $B$. cepacia cytokine stimulation is unclear, but is independent of CD14 receptors. Of interest, induction of TNF $\alpha$ by $B$. cepacia LPS is reduced in the presence of $P$. aeruginosa LPS, suggesting that the diversity of clinical outcomes in patients colonised with $B$. cepacia may be influenced in part by the presence or absence of $P$. aeruginosa and other CF pathogens [105].

\section{What is a true $B$. cepacia?}

Further research to establish a gold standard for laboratory identification of B. cepacia has assumed high priority. Reliable identification is important not only in attempts to clarify the organism's pathogenic potential, but also because of the clinical, social, psychological and potentially litigious consequences for patients, carers and diagnostic laboratories associated with the organism's acquisition and transmission. Selective media and laboratory protocols for culture and presumptive identification of $B$. cepacia from clinical or environmental sources have been described and their value in microbiological surveillance established [14, 48, 56, 106]. However, existing selective media also support the growth of other gram-negative non-fermenting bacilli $[46,48,56]$ and unequivocal identification of $B$. cepacia by multitest commercial systems can present difficulties $[44,56,106,107]$.

There is increasing evidence that organisms presently identified as $B$. cepacia by standard laboratory procedures exhibit such diverse genotypic and phenotypic properties that attempts to generalise on virulence, transmission and antibiotic susceptibility are ill-founded. Simpson et al. [44] speculated that epidemic strains may represent a $B$. cepacia sub- 
population, arising as bacterial hybrids or through horizontal transfer of virulence genes from the closely related pseudomonads $B$. gladioli and the highly dangerous intracellular pathogen $B$. pseudomallei. Recently, isolates identified as $B$. cepacia were characterised further by analysis of cellular proteins and fatty acid components and clustered by means of computer-assisted numerical comparison of the profiles. Representative isolates from individual clusters were selected to determine genotypic relatedness within and between clusters by means of DNADNA and DNA-rRNA hybridisation assays. These molecular phylogenetic studies revealed that organisms identified by conventional tests as $B$. cepacia comprised several new Burkholderia spp. [108].

According to taxonomic conventions, new species names should not be given to bacteria that cannot be identified reliably by phenotypic characteristics; instead, such groups can be described by the terms genomovar I, II, etc. [109]. Following this convention, isolates identified as $B$. cepacia by conventional multitest systems such as the API 20NE system (API-bioMerieux, Marcyl'Etoile, France) constitute at least four different genomovars of $B$. cepacia; other presumed $B$. cepacia strains are identified as the nitrogen-fixing organism $B$. vietnamiensis. Preliminary studies on a small number of isolates have indicated that the majority of $\mathrm{CF}$ isolates from Belgium and the UK tend to cluster in genomovar III $[70,108]$. Subsequent ongoing analyses of a larger collection of environmental, phytopathogenic and clinical isolates in our laboratories have confirmed the potential importance of genomovar identification. For example, the isolate responsible for the first UK report of cepacia syndrome [72], and three individual epidemic clones including the highly transmissible ET12 lineage $[25,44,62,69]$ each belong to genomovar III. It should be stressed that $B$. vietnamiensis and the remaining $B$. cepacia genomovars were also identified amongst isolates from $\mathrm{CF}$ patients, and that genomovar III status is not synonymous with high transmissibility [72]. Of the 150 ' $B$. cepacia' isolates studied to date, most environmental isolates (including the phytopathogenic type strain ATCC 25416) belong to genomovar I; in contrast, isolates associated with acute clinical decline in $\mathrm{CF}$ patients are restricted to genomovar III. These results confirm the complex taxonomic heterogeneity within the genus Burkholderia and have important diagnostic implications for infection control in the $\mathrm{CF}$ community.

\section{Unique bacterial clones and $B$. cepacia transmission factors}

Epidemiological data and genomic fingerprinting suggest that the variable incidence of $B$. cepacia-in particular, the lack of cross-infection in some centres
[75,81], and the contrasting epidemic spread in others-reflects the behaviour of a relatively small number of highly transmissible clones $[46,69,110-$ 112].

It seems reasonable to speculate that $B$. cepacia strains responsible for epidemic spread may harbour a common colonising factor whose identification could be exploited for diagnostic and therapeutic purposes. At present, the most significant of these factors is adhesion to respiratory mucin [53,113-115], associated with giant intertwined fibres referred to as cable pili $[53,114]$. The gene responsible for cable pili, $c b l$, has been detected in the highly transmissible ET12 lineage, represented by the Edinburgh isolate CF5610 (J2315) [16, 25, 62, 69, 115], and responsible for $B$. cepacia colonisation in $38 \%$ of UK patients [46]. In a slightly different form, $c b l$ has also been associated with epidemic transfer of $B$. cepacia from CF to nonCF patients in a Mississippi outbreak [16,69, 115]. However, studies with a $c b l$ DNA probe indicated that $c b l$ is not present in all epidemic clones, suggesting that other bacterial and host factors need to be identified [69]. Interestingly, a recent study [116] has described enhanced binding of the ET12 lineage to lipid receptors, particularly the galactolipid globotriosylceramide $\left(\mathrm{GB}_{3}\right)$, and led to speculation that upregulation of $\mathrm{GB}_{3}$, mediated through the infection process and TNF stimulation within the lung, may provide an alternative receptor for isolates in which cable pili are poorly expressed and a second receptor system for the epithelial attachment of bacteria that have migrated through the mucosal blanket.

Experimental proof of direct or indirect transmission of epidemic $B$. cepacia is not feasible and can be judged only by circumstantial evidence. However, epidemiological data has strikingly demonstrated such potential. Colonisation with more than one strain of $B$. cepacia is unusual and has been reported in $<10 \%$ of patients [46]. During the Edinburgh outbreak, PFGE fingerprinting showed that one patient harboured two B. cepacia strains in his respiratory secretions, including the ET12 clone; however, only the epidemic strain was transmitted subsequently to his girlfriend [62].

\section{Modes of transmission and the risks of acquisition}

The potential risks of $B$. cepacia transmission, either directly by person-to-person spread or indirectly from contaminated fomites, continue to be a major concern to the $\mathrm{CF}$ community. Table 2 summarises the extensive documented evidence for direct transmission of $B$. cepacia between $\mathrm{CF}$ patients during close contacts within hospitals $[61,63,65]$, at educational or summer camps $[59,66]$ and through other social contacts $[62,63]$; in contrast, several reliable studies have found no evidence of cross-infection [72-75]. In 
their initial report, LiPuma et al. [59] cited previous failures to culture $B$. cepacia from respiratory equipment and environmental surfaces as circumstantial evidence that direct person-to-person spread might be the primary means of transmission. However, a subsequent prospective study [117] with selective culture and DNA-based typing of isolates showed that colonised patients can contaminate their environment; thus indirect transmission might occur via contaminated surfaces. The intrinsic resistance of $B$. cepacia to many antibiotics also raised justifiable concern that the use of contaminated home-use nebulisers might present a special hazard for B. cepacia acquisition. Currently, evidence for nebuliser-associated transmission is scanty and equivocal. A case-controlled retrospective study of five $\mathrm{CF}$ patients undergoing treatment in a $\mathrm{CF}$ centre [118] showed a significant association between outpatient nebuliser use and $B$. cepacia colonisation. $B$. cepacia was also cultured from nebulisers used by colonised patients. Unfortunately, no bacterial typing was performed to confirm the clonal relationships of the human and nebuliser isolates. Recently, in a prospective study [119], B. cepacia was cultured from three of 35 home-use nebulisers. DNA macrorestriction analysis by PFGE revealed that one of two strains of $B$. cepacia recovered from the nebuliser of one patient was also present in the patient's sputum. However, sputum cultures from the two other patients whose nebulisers harboured $B$. cepacia did not yield the organism, suggesting an environmental origin for the $B$. cepacia strain isolated from the nebuliser. Other studies of nosocomial acquisition of $B$. cepacia in non$C F$ patients have suggested that respiratory infection probably occurred by indirect transmission following use of contaminated nebuliser devices [31, 120]. Airborne dissemination may also present a small risk of $B$. cepacia acquisition. In a prospective study, B. cepacia was recovered from the room air during occupation by five of six patients, but to only a limited extent, with the number of bacteria ranging from 1 to $158 \mathrm{cfu} / \mathrm{m}^{3}$ [121]. Maximum yields were associated with episodes of coughing and, after a patient left the room, the organism persisted in room air for up to $45 \mathrm{~min}$.

To conclude, ethical considerations prevent experi- ments that could provide scientific data to assess the risks of $B$. cepacia acquisition, including clarification of the frequency of contact and the infectious dose required. Based on accumulated evidence (Tables 2 and 3 ), skin contact, respiratory aerosols, sharing food, contaminated equipment, co-habitation or undergoing physiotherapy in the same room as a $B$. cepaciapositive individual present reasonable risks of acquisition. However, epidemiological evidence [38,62], including the high numbers (typically $>10^{8} \mathrm{cfu} / \mathrm{ml}$ ) of $B$. cepacia present in the saliva of colonised patients, suggests that the close and frequent social contact that occurs between siblings, the direct exchange of respiratory secretions associated with kissing, and the involvement of a highly transmissible $B$. cepacia lineage arguably present the greatest risks of acquisition.

\section{Environmental release of $B$. cepacia as a biological control agent}

Whilst the CF community debates the clinical issues of $B$. cepacia colonisation and transmission, agricultural microbiologists continue to develop the organism as a biological control agent to exploit its antifungal activity (Fig. 1) for the enhancement of crop yields [122, 123] and its nutritional adaptability in the bioremediation of landfill sites, contaminated soils and ground water aquifers [124-126]. Deliberate environmental distribution of $B$. cepacia as field inoculants raises the issue of the phylogenetic relationship between $B$. cepacia of environmental and clinical origin and the potential hazard for human infection. The debate on this relationship has revealed the gulf that exists between different areas of interest and microbiological expertise and, as stated recently in an editorial comment on another contentious issue, bovine spongiform encephalopathy, 'underscores the weakness of separating agricultural and medical science' [127].

We have stated previously that the scientific evidence that environmental strains of $B$. cepacia present little hazard to man is weak [14] and is based on examination of only a few bacterial isolates and

Table 3. Factors that may influence acquisition of $B$. cepacia

- In colonised individuals, B. cepacia saliva counts can exceed $10^{8} \mathrm{cfu} / \mathrm{ml}$, suggesting that the highest risk of patient-to-patient spread is transmission of respiratory secretions during kissing or through sharing of eating or drinking utensils.

- Spirometer mouthpieces become heavily contaminated during lung function tests. Risk avoided by use of disposable mouthpieces. Recovery from the surface of lung function equipment is low.

- Recovery from antibiotic reservoirs of nebulisers has been reported, but incidence is low and the degree of risk appears secondary to the preceding factors.

- Aerosol recovery is low, suggesting low risk of aerosol transmission.

- Hands become contaminated after coughing and the organism can be transmitted by handshake. Survival on hands reduced to $10 \%$ after $30 \mathrm{~min}$; this varies in different individuals and may account for variable recovery in surveillance studies.

- Gastrointestinal carriage has not been demonstrated, even in colonised individuals, suggesting that the risk of faecal-oral spread is minimal.

- After surface contamination with B. cepacia-containing sputum, viable bacteria can be recovered for several weeks

- Surface contamination by B. cepacia sputum is eliminated by treatment with UV irradiation and with common hospital disinfectants, including Milton, Dettol, alcohol $70 \%$, phenols, iodine and cetrimide. Careful drying is important after washing or disinfection.

- Recovery of B. cepacia from soil, plants, drains, lakes and surface waters is low, suggesting that natural environments present a possible but low risk for acquisition. 


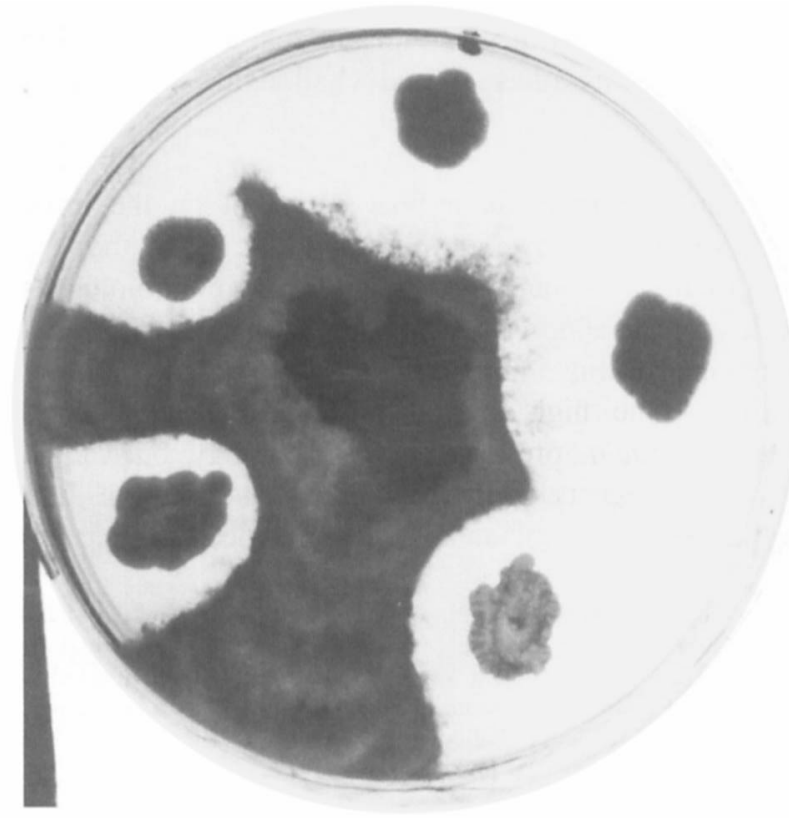

Fig. 1. Inhibition of the phytopathogenic fungus Rhizoctonia solani by five isolates of $B$. cepacia. The fungus was inoculated in the centre of the plate and bacteria around the perimeter. Cultures were photographed after incubation for 14 days at room temperature.

inappropriate bacterial properties [24]. Although some studies have indicated that environmental and clinical isolates are distinct, no reliable phenotypic markers have been identified $[25,45,108]$. The suggestion that clinical isolates can be distinguished from soil isolates based on the former's lack of plant pathogenicity [45] is discounted by the fact that CF isolates of $B$. cepacia will readily macerate onion tissue (Fig. 2) [14]. In addition, the invasive $B$. cepacia foot lesions known as swamp foot [128], acquired by military personnel during jungle training, confirm the pathogenic potential of environmental strains of $B$. cepacia for man.

The potential hazard that some or all environmental $B$. cepacia strains present to the $\mathrm{CF}$ community is unclear and requires investigation. The fact that new cases of $B$. cepacia colonisation continue to occur with strains that show no genotypic relationship to other isolates within the same CF centre, points to the environment as a potential source. However, the extent of this risk is difficult to assess. Extensive microbiological safaris into supermarkets and domestic homes [15], and a range of botanical soils and cultivars [14], indicate that $B$. cepacia can be cultured from up to $20 \%$ of warm moist environmental sites, particularly soils, but that it is not as ubiquitous as other pseudomonads. Interestingly, in our studies to date, none of the environmental isolates of $B$. cepacia have been identified as belonging to genomovar III.

\section{Conclusions and future prospects}

B. cepacia is a striking example of a multiresistant soil saprophyte and phytopathogen that has emerged as an important threat to susceptible human hosts. In the CF community, the degree to which infection control measures should be implemented continues to arouse strong scientific and social debate. The validity of strict control is supported by circumstantial, but nevertheless compelling, evidence for direct person-to-person transmission of epidemic strains through nosocomial and social contact. In contrast, although the risk of indirect iatrogenic spread from contaminated fomites remains

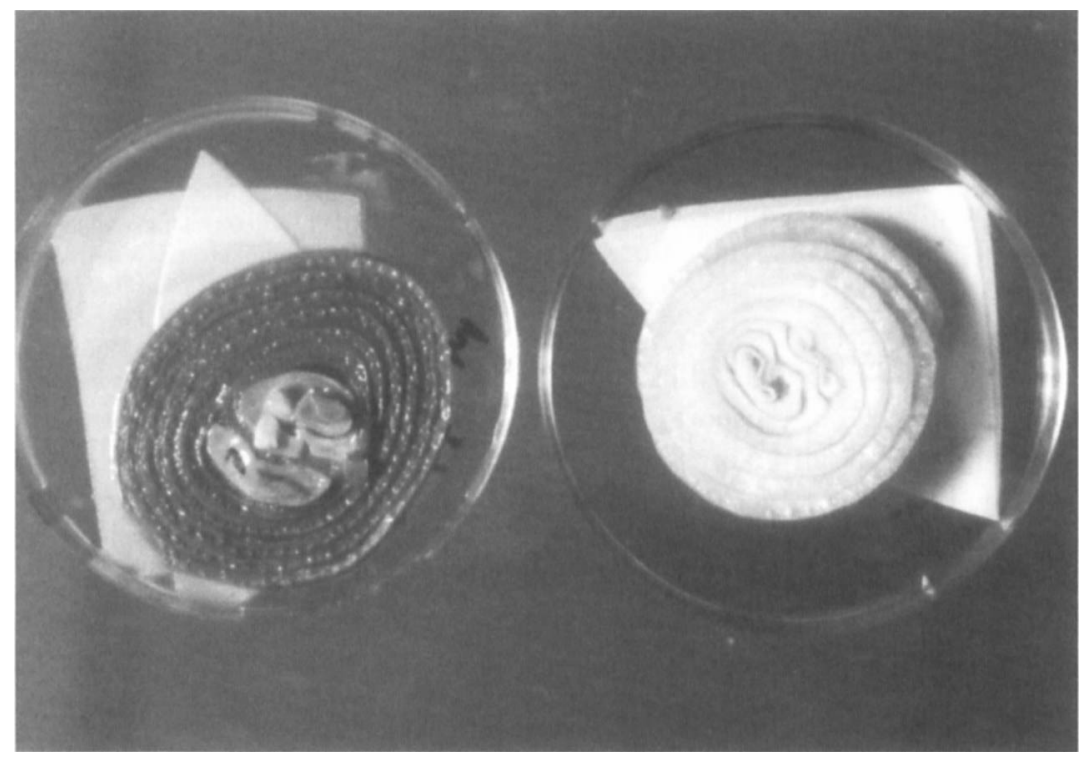

Fig. 2. Soft rot of a segmented 'compromised' onion inoculated with a clinical B. cepacia isolate of the epidemic ET12 lineage (left) and an uninoculated control (right), both incubated at $30^{\circ} \mathrm{C}$ for $72 \mathrm{~h}$. Reproduced with permission from Butler et al. [14]. 
unclear, available evidence suggests that this route is less important than direct transfer. An important caveat in attempts to generalise on B. cepacia transmission is evidence that the major epidemics of $B$. cepacia involve a subpopulation of highly epidemic lineages which might be re-allocated ultimately to new species; 'Burkholderia cfei' might be an appropriate but probably controversial choice! Ongoing microbiological surveillance in $\mathrm{CF}$ centres indicates that sporadic acquisition of epidemic lineages continues to occur when there is a failure to comply with infection control measures. For example, a striking demonstration of the continued potential for transmission of the ET12 lineage was its recent acquisition by an Edinburgh $\mathrm{CF}$ adult; extensive inquiries suggested that this patient had social contact for only $10 \mathrm{~min}$ whilst visiting another CF male who was hospitalised during an episode of $B$. cepacia septicaemia. Even when infection control appears effective in preventing spread of epidemic lineages, new cases of $B$. cepacia colonisation continue to occur with isolates that exhibit unique PCR ribotyping or PFGE profiles. Such sporadic acquisitions raise a fundamental question concerning the source and colonising potential of individual $B$. cepacia strains. For example, does the environment contain a subpopulation of $B$. cepacia clones that are innately primed for human colonisation, or does colonisation and virulence in man require in-vivo adaptation? Future improvements in laboratory identification of $B$. cepacia subpopulations associated with CF disease and identification of transmission factors, in addition to cable pili, may provide scientific justification for relaxation of segregation in the absence of known epidemic and potentially virulent lineages. Turning our attention to $\mathrm{CF}$ patients, we need to clarify why colonisation by the same strain of $B$. cepacia leads to variable clinical responses, ranging from asymptomatic colonisation to rapid fatal pulmonary deterioration. It could be argued that this particular problem is not unique to $B$. cepacia, and that applying Koch's postulates in an attempt to distinguish between sycophancy and pathogenic potential is difficult when dealing with any opportunist pathogen. Certainly, host factors cannot be ignored in attempts to understand the pathogenic processes involved in CF lung infections.

During the final preparation of this review, a deceptively simple and elegant study has illustrated how CFTR-associated defective $\mathrm{Cl}^{-}$transport across airway epithelia might lead to bacterial colonisation in CF patients. Smith et al. [129] showed that the normal human apical epithelial surface is bactericidal for $P$. aeruginos $a$ and $S$. aureus; in contrast, the bactericidal activity was inhibited reversibly in CF epithelia because of a high $\mathrm{NaCl}$ concentration. If this phenomenon varies in individual CF patients-or if individual $B$. cepacia strains differ in susceptibility to the defensin-like bactericidal agent-it might explain some of the host- and pathogen-specific anomalies associated with $B$. cepacia pulmonary infection and suggest novel strategies for infection control and therapy of this unusual and challenging opportunist pathogen.

It is difficult to avoid a final comment on the irony that whilst $B$. cepacia continues to hold the $C F$ community to ransom, agricultural microbiologists seek to develop the commercial and beneficial potential of this microbial Jekyll and Hyde in their search for biological control agents. This situation demonstrates the diversity of microbiology, but should also encourage attempts to reduce the present gulf between agricultural and medical science.

Studies by J.R.W.G. and J.E.H. were supported by grants from the Cystic Fibrosis Trust and the Medical Research Council. J.E.H. is supported by a MRC Clinical Training Fellowship. P.V. is indebted to the National Fund for Scientific Research (Belgium) for a position as a postdoctoral research fellow. Special thanks are due to our laboratory colleagues past and present.

\section{References}

1. Beckman W, Lessie TG. Response of Pseudomonas cepacia to $\beta$-lactam antibiotics: utilization of penicillin $\mathrm{G}$ as the carbon source. J Bacteriol 1979; 140: 1126-1128.

2. Burkholder WH. Sour skin, a bacterial rot of onion bulbs. Phytopath 1950; 40: 115-117.

3. Yabuuchi E, Kosako Y, Oyaizu $\mathrm{H}$ et al. Proposal of Burkholderia gen. nov. and transfer of seven species of the genus Pseudomonas homology group Il to the new genus, with the type species Burkholderia cepacia (Palleroni and Holmes 1981) comb. nov. Microbiol Immunol 1992; 36: $1251-1275$.

4. Urakami T, Ito-Yoshida C, Araki H, Kijima T, Suzuki K-I, Komagata K. Transfer of Pseudomonas plantarii and Pseudomonas glumae to Burkholderia as Burkholderia spp. and description of Burkholderia vandii $\mathrm{sp}$. nov. Int $J$ Syst Bacteriol 1994; 44: 235-245.

5. Zhao NX, Qu CF, Wang ET, Chen WX. Phylogenetic evidence for the transfer of Pseudomonas cocovenenans (vanDamme et al 1960) to the genus Burkholderia as Burkholderia cocovenenans (vanDamme et al 1960) comb. nov. Int $J$ Syst Bacteriol 1995; 45: 600-603.

6. Gillis M, Van T, Bardin R et al. Polyphasic taxonomy in the genus Burkholderia leading to an emended description of the genus and proposition of Burkholderia vietnamiensis sp. nov. for $\mathrm{N}_{2}$-fixing isolates from rice in Vietnam. Int $J$ Syst Bacteriol 1995; 45: 274-289.

7. Palleroni NJ. Genus I. Pseudomonas. In: Krieg NR, Holt JG (eds) Bergey's Manual of systemic bacteriology, vol 1 . Baltimore, Williams and Wilkins Co. 1984: 141-159.

8. Wise MG, Shimkets LJ, McArthur JV. Genetic structure of a lotic population of Burkholderia (Pseudomonas) cepacia. Appl Environ Microbiol 1995; 61: 1791-1798.

9. Cheng H-P, Lessie TG. Multiple replicons constituting the genome of Pseudomonas cepacia 17616. J Bacteriol 1994; 176: $4034-4042$

10. Rodley PD, Römling U, Tümmler B. A physical genome map of the Burkholderia cepacia type strain. Mol Microbiol 1995; 17: $57-67$.

11. Holmes B. The identification of Pseudomonas cepacia and its occurrence in clinical material. J Appl Bacteriol 1986; 61: 299-314.

12. Pitchford KC, Corey M, Highsmith AK et al. Pseudomonas species contamination of cystic fibrosis patients' home inhalation equipment. $J$ Pediatr 1987; 111: 212-216.

13. Fisher MC, LiPuma JJ, Dasen SE et al. Source of Pseudomonas cepacia: ribotyping of isolates from patients and from the environment. $J$ Pediatr 1993; 123: 745-747.

14. Butler SL, Doherty CJ, Hughes JE, Nelson JW, Govan JRW. Burkholderia cepacia and cystic fibrosis: do natural environments present a potential hazard? J Clin Microbiol 1995; 33: 
$1001-1004$

15. Mortensen JE, Fisher MC, LiPuma JJ. Recovery of Pseudomonas cepacia and other Pseudomonas species from the environment. Infect Control Hosp Epidemiol 1995; 16: $30-32$.

16. Holmes A, Nolan R, Taylor $\mathrm{R}$ et al. An epidemic of Burkholderia (Pseudomonas) cepacia affecting patients with cystic fibrosis and without cystic fibrosis. Lancet (in press).

17. Govan JRW, Harris G. Typing of Pseudomonas cepacia by bacteriocin susceptibility and production. J Clin Microbiol 1985; 22: 490-494.

18. McLoughlin TJ, Quinn JP, Bettermann A, Bookland R. Pseudomonas cepacia suppression of sunflower wilt fungus and role of antifungal compounds in controlling the disease. Appl Environ Microbiol 1992; 58: 1760-1763.

19. Jayaswal RK, Fernandez M, Upadhyay RS et al. Antagonism of Pseudomonas cepacia against phytopathogenic fungi. Curr Microbiol 1993; 26: 17-22.

20. Abe M. Nakazawa T. Characterization of hemolytic and antifungal substance, cepalycin, from Pseudomonas cepacia. Microbiol Immunol 1994; 38: 1-9.

21. Aoki M, Uehara K, Tsuji K, Ono K, Iijima M. Large-scale culture and preservation methods of Pseudomonas cepacia B5 for biological control against bacterial wilt disease Bioscience Biotech Biochem 1993; 57: 668-669.

22. Folsom BR, Chapman PJ, Pritchard PH. Phenol and trichloroethylene degradation by Pseudomonas cepacia G4: kinetics and interactions between substrates. Appl Environ Microbiol 1990; 56: 1279-1285.

23. Kilbane JJ, Chatterjee DK, Karns JS, Kellogg ST, Chakrabarty AM. Biodegradation of 2,4,5-trichlorophenoxyacetic acid by pure culture of Pseudomonas cepacia. Appl Environ Microbiol 1982; 44: 72-78.

24. Bevivino A, Tabacchioni S, Chiarni L, Carusi MV, del Gallo M. Visca P. Phenotypic comparison between rhizosphere and clinical isolates of Burkholderia cepacia. Microbiology 1994; 140: $1069-1077$.

25. Johnson WM, Tyler SD, Rozee KR. Linkage analysis of geographical and clinical clusters in Pseudomonas cepacia infections by multilocus enzyme electrophoresis and ribotyping. J Clin Microbiol 1994; 32: 924-930.

26. Govan JRW, Deretic V. Microbial pathogenesis in cystic fibrosis: Mucoid Pseudomonas aeruginosa and Burkholderia cepacia. Microbiol Rev (in press)

27. Dailey RH, Benner EJ. Necrotizing pneumonitis due to the pseudomonad "eugonic oxidizer-group 1". N Engl J Med 1968; 279: 361-362.

28. Basset DCJ, Stokes KJ, Thomas WRG. Wound infection with Pseudomonas multivorans: a water-borne contaminant of disinfectant solutions. Lancet 1970; 1: 1188-1191.

29. Phillips I, Eykyn S, Curtis MA, Snell JJS, Pseudomonas cepacia (multivorans) septicaemia in an intensive-care unit. Lancet 1971; 1: 375-377.

30. Cabrera HA, Drake MA. An epidemic in a coronary care unit caused by Pseudomonas species. Am J Clin Pathol 1975; 64: $700-704$.

31. Poe RH, Marcus HR, Emerson GL. Lung abscess due to Pseudomonas cepacia. Am Rev Respir Dis 1977; 115: 861 865 .

32. Goldman DA, Klinger JD. Pseudomonas cepacia: biology, mechanisms of virulence, epidemiology. $J$ Pediatr 1986; 108 806-812.

33. Jarvis WR, Olson D, Tablan O, Martone WJ. The epidemiology of nosocomial Pseudomonas cepacia infections: endemic infections. Eur J Epidemiol 1987; 3: 233-236.

34. Martone WJ, Tablan OC, Jarvis WR. The epidemiology of nosocomial epidemic Pseudomonas cepacia infections. Eur $J$ Epidemiol 1987; 3: 222-232

35. O'Neil KM, Herman JH, Modlin JF, Moxon ER, Winkelstein JA. Pseudomonas cepacia: an emerging pathogen in chronic granulomatous disease. J Pediatr 1986; 108: 940-942.

36. Lacy DE, Spencer DA, Goldstein A, Weller PH, Darbyshire P. Chronic granulomatous disease presenting in childhood with Pseudomonas cepacia septicaemia. J Infect 1993; 27: 301-304.

37. Isles A, Maclusky I, Corey M et al. Pseudomonas cepacia infection in cystic fibrosis: an emerging problem. $J$ Pediatr 1984; 104: 206-210.

38. Thomassen MJ, Demko CA, Klinger JD, Stern RC
Pseudomonas cepacia colonization among patients with cystic fibrosis. A new opportunist. Am Rev Respir Dis 1985; 131 791-796.

39. Anonymous. (Editorial). Pseudomonas cepacia - more than a harmless commensal? Lancet 1992; 339: 1385-1386.

40. Wong SN, Tam AY, Yung RW, Kwan EY, Tsoi NN Pseudomonas septicemia in apparently healthy children. Acta Paediatr Scand 1991; 80: 515-520.

41. Pujol M, Corbella X, Carratala J, Gudiol F. Communityacquired bacteremic Pseudomonas cepacia pneumonia in an immunocompetent host. Clin Infect Dis 1992; 15: 887-888.

42. Hobson R, Gould I, Govan J. Burkholderia (Pseudomonas) cepacia as a cause of brain abscesses secondary to chronic suppurative otitis media. Eur J Clin Microbiol Infect Dis 1995; 14: 908-911.

43. LiPuma JJ, Fisher MC, Dasen SE, Mortensen JE, Stull TL. Ribotype stability of serial pulmonary isolates of Pseudomonas cepacia. J Infect Dis 1991; 164: 133-136.

44. Simpson IN, Finlay J, Winstanley DJ et al. Multi-resistance isolates possessing characteristics of both Burkholderia (Pseudomonas) cepacia and Burkholderia gladioli from patients with cystic fibrosis. J Antimicrob Chemother 1994; 34: $353-361$.

45. Yohalem DS, Lorbeer JW. Multilocus isoenzyme diversity among strains of Pseudomonas cepacia isolated from decayed onions, soils, and clinical sources. Syst Appl Microbiol 1994; 17: 116-124.

46. Pitt TL, Kaufmann ME, Patel PS, Benge LCA, Gaskin S, Livermore DM. Type characterisation and antibiotic susceptibility of Burkholderia (Pseudomonas) cepacia isolates from patients with cystic fibrosis in the United Kingdom and the Republic of Ireland. J Med Microbiol 1996; 44: 203-210.

47. Scordilis GE, Ree H, Lessie TG. Identification of transposable elements which activate gene expression in Pseudomonas cepacia. J Bacteriol 1987; 169: 8-13.

48. Gilligan PH. Microbiology of airway disease in patients with cystic fibrosis. Clin Microbiol Rev 1991; 4: 35-51.

49. Govan JRW, Nelson JW. Microbiology of cystic fibrosis lung infections: themes and issues. $J R$ Soc Med 1993; 86 Suppl 20: $11-18$.

50. Govan JRW, Glass S. The microbiology and therapy of cystic fibrosis lung infections. Rev Med Microbiol 1990; 1: 19-28.

51. Simmonds EJ, Conway SP, Ghoneim ATM, Ross H, Littlewood JM. Pseudomonas cepacia: a new pathogen in patients with cystic fibrosis referred to a large centre in the United Kingdom. Arch Dis Child 1990; 65: 874-877.

52. Gladman G, Connor PJ, Williams RF, David TJ. Controlled study of Pseudomonas cepacia and Pseudomonas maltophilia in cystic fibrosis. Arch Dis Child 1992; 67: 192-195.

53. Sajjan US, Corey M, Karmali MA, Forstner JF. Binding of Pseudomonas cepacia to normal human intestinal mucin and respiratory mucin from patients with cystic fibrosis. $J$ Clin Invest 1992; 89: 648-656.

54. Lewin C, Doherty C, Govan JRW. In vitro activities of meropenem, PD 127391, PD 131628, ceftazidime, chloramphenicol, co-trimoxazole, and ciprofloxacin against Pseudomonas cepacia. Antimicrob Agents Chemother 1993; 37: $123-125$.

55. Tablan OC, Carson LA, Cusick LB, Bland LA, Martone WJ, Jarvis WR. Laboratory proficiency test results on use of selective media for isolating Pseudomonas cepacia from simulated sputum specimens of patients with cystic fibrosis. $J$ Clin Microbiol 1987; 25: 485-487.

56. Pitt TL, Govan JRW. Pseudomonas cepacia and cystic fibrosis. PHLS Microbiol Dig 1993; 10: 69-72.

57. Thomassen MJ, Demko CA, Doershuk CF, Stern RC, Klinger JD. Pseudomonas cepacia: decrease in colonization in patients with cystic fibrosis. Am Rev Respir Dis 1986; 134: 669-671.

58. LiPuma JJ, Mortensen JE, Dasen SE et al. Ribotype analysis of Pseudomonas cepacia from cystic fibrosis treatment centers. J Pediatr 1988; 113: 859-862.

59. LiPuma JJ, Dasen SE, Nielson DW, Stern RC, Stull TL Person-to-person transmission of Pseudomonas cepacia between patients with cystic fibrosis. Lancet 1990; 336: 1094 1096.

60. Anderson DJ, Kuhns JS, Vasil ML, Gerding DN, Janoff EN. DNA fingerprinting by pulsed field gel electrophoresis and ribotyping to distinguish Pseudomonas cepacia from a 
nosocomial outbreak. J Clin Microbiol 1991; 29: 648-649.

61. Millar-Jones L, Paull A, Saunders Z, Goodchild MC. Transmission of Pseudomonas cepacia among cystic fibrosis patients. Lancet 1992; 340: 491.

62. Govan JRW, Brown $\mathrm{PH}$, Maddison $\mathrm{J}$ et al. Evidence for transmission of Pseudomonas cepacia by social contact in cystic fibrosis. Lancet 1993; 342: 15-19.

63. Smith DL, Gumery LB, Smith EG, Stableforth DE, Kaufmann ME, Pitt TL. Epidemic of Pseudomonas cepacia in an adult cystic fibrosis unit: evidence of person-to-person transmission. J Clin Microbiol 1993; 31: 3017-3022.

64. Bingen $\mathrm{E}$, Botzenhart $\mathrm{K}$, Chabanon $\mathrm{G}$ et al. Epidemiology of pulmonary infections by Pseudomonas in patients with cystic fibrosis: a consensus report. French Cystic Fibrosis Association (AFLM), Paris, 1993.

65. Corkill JE, Sisson PR, Smyth A et al. Application of pyrolysis mass spectroscopy and SDS-PAGE in the study of the epidemiology of Pseudomonas cepacia in cystic fibrosis. $J$ Med Microbiol 1994; 41: 106-111.

66. Pegues DA, Carson LA, Tablan OC et al. Acquisition of Pseudomonas cepacia at summer camps for patients with cystic fibrosis. Summer Camp Study Group. J Pediatr 1994; 124: $694-702$.

67. LiPuma JJ, Marks-Austin KA, Holsclaw DS, Winnie GB, Gilligan PH, Stull TL. Inapparent transmission of Pseudomonas (Burkholderia) cepacia among patients with cystic fibrosis. Pediatr Infect Dis J 1994; 13: 716-719.

68. Ryley HC, Millar-Jones L, Paull A, Weeks J. Characterisation of Burkholderia cepacia from cystic fibrosis patients living in Wales by PCR ribotyping. $J$ Med Microbiol 1995; 43: $436-441$

69. Sun L, Jiang R-Z, Steinbach S et al. The emergence of a highly transmissible lineage of $\mathrm{cbl}^{+}$Pseudomonas (Burkholderia) cepacia causing CF centre epidemics in North America and Britain. Nature Med 1995; 1: 661-666.

70. Revets H, Lauwers S. Molecular epidemiology of Burkholderia (Pseudomonas) cepacia. 20th European Cystic Fibrosis Conference, Brussels 1995: L21.

71. Whiteford ML, Wilkinson JD, McColl JH et al. Outcome of Burkholderia (Pseudomonas) cepacia colonisation in children with cystic fibrosis following a hospital outbreak. Thorax 1995; 50: 1194-1198.

72. Glass S, Govan JRW. Pseudomonas cepacia - fatal pulmonary infection in a patient with cystic fibrosis. $J$ Infect 1986; 13: $157-158$.

73. Hardy KA, McGowan KL, Fisher MC, Schidlow DV. Pseudomonas cepacia in the hospital setting; lack of transmission between cystic fibrosis patients. $J$ Pediatr 1986; 109: 51-54.

74. Taylor CJ, Howden R, Smith T, Spencer RC. Pseudomonas cepacia. Arch Dis Child 1994; 70: 358.

75. Steinbach S, Sun L, Jiang R-Z et al. Transmissibility of Pseudomonas cepacia infection in clinic patients and lungtransplant recipients with cystic fibrosis. N Engl J Med 1994; 331: 981-987.

76. Cystic Fibrosis statement on Pseudomonas cepacia. Newsletter of the Association of Cystic Fibrosis Adults (UK). 1993; 37: 2-5.

77. Muhdi K, Edenborough FP, Gumery L et al. Outcome for patients colonised with Burkholderia cepacia in a Birmingham adult cystic fibrosis clinic and the end of an epidemic. Thorax 1996; 51: 374-377.

78. Tablan OC, Chorba TL, Schidlow DV et al. Pseudomonas cepacia colonization in patients with cystic fibrosis: risk factors and chinical outcome. J Pediatr 1985; 107: 382-387.

79. Lewin LO, Byard PJ, Davis PB. Effect of Pseudomonas cepacia colonization on survival and pulmonary function of cystic fibrosis patients. J Clin Epidemiol 1990; 43: 125-131.

80. Brown P, Butler S, Nelson J, Doherty C, Govan J, Greening A. Pseudomonas cepacia (PC) in adult cystic fibrosis (CF): accelerated decline in lung function and increased mortality. Thorax 1993; 48: 425-426.

81. Taylor RFH, Gaya H, Hodson ME. Pseudomonas cepacia: pulmonary infection in patients with cystic fibrosis. Respir Med 1993; 87: 187-192.

82. Davidson DJ, Dorin JR, McLachlan G et al. Lung disease in the cystic fibrosis mouse exposed to bacterial pathogens. Nature Genetics 1995; 9: 351-357.

83. Nelson JW, Butler SL, Krieg D, Govan JRW. Virulence factors of Burkholderia cepacia. FEMS Immunol Med Microbiol 1994; 8: 89-97.

84. Wilkinson SG, Pitt TL. Burkholderia (Pseudomonas) cepacia: pathogenicity and resistance. Rev Med Microbiol 1995; 6: $10-17$.

85. Speert DP, Bond M, Woodman RC, Curnutte JT. Infection with Pseudomonas cepacia in chronic granulomatous disease: role of nonoxidative killing by neutrophils in host defense $J$ Infect Dis 1994; 170: 1524-1531.

86. Butler SL, Nelson JW, Poxton IR, Govan JRW. Serum sensitivity of Burkholderia (Pseudomonas) cepacia isolates from patients with cystic fibrosis. FEMS Immunol Med Microbiol 1994; 8: 285-292.

87. Nelson JW, Butler SL, Brown PH, Greening AP, Govan JRW. Serum IgG and sputum IgA antibody to core lipopolysaccharide antigen from Pseudomonas cepacia in patients with cystic fibrosis. J Med Microbiol 1993; 39: 39-47.

88. Pruksachartvuthi S, Aswapokee N, Thankerngpol K. Survival of Pseudomonas pseudomallei in human phagocytes. $J$ Med Microbiol 1990; 31: 109-114.

89. Burns JL. Characterization of invasion of epithelial cells by Pseudomonas cepacia. Pediatr Pulmonol 1992; Suppl 8: abstract 201.

90. Tipper JL, Ingham E, Cove JH, Todd NJ, Littlewood JM. Kerr $\mathrm{KG}$. An immunofluorescent assay for determining the invasiveness of A549 cells by Burkholderia (Pseudomonas) cepacia. 20th European Cystic Fibrosis Conference, Brussels 1995: P15.

91. Miller VL. Tissue-culture invasion: fact or artefact. Trends Microbiol 1995; 3: 69-71.

92. Pier GB, Grout M, Zaidi TS et al. Role of mutant CFTR in hypersusceptibility of cystic fibrosis patients to lung infections. Science 1996; 271: 64-67.

93. Landers PD, Tipper JL, Rowbotham TJ, Kerr KG. Survival and multiplication of Burkholderia (Pseudomonas) cepacia within the free-living amoeba Acanthamoeba polyphaga. 20th European Cystic Fibrosis Conference, Brussels 1995: P4.

94. Aronoff SC, Quinn FJ, Stern RC. Longitudinal serum IgG response to Pseudomonas cepacia surface antigens in cystic fibrosis. Pediatr Pulmonol 1991; 11: 289-293.

95. Aronoff SC, Stern RC. Serum IgG antibody to outer membrane antigens of Pseudomonas cepacia and Pseudomonas aeruginosa in cystic fibrosis. $J$ Infect Dis 1988; 157: 934-940.

96. Lacy DE, Smith AW, Stableforth DE, Smith G, Weller PH, Brown MRW. Serum IgG response to Burkholderia cepacia outer membrane antigens in cystic fibrosis: assessment of cross-reactivity with Pseudomonas aeruginosa. FEMS Immunol Med Microbiol 1995; 10: 253-262.

97. Burnie JP, Al-Wardi EJ, Williamson P, Matthews RC, Webb $\mathrm{K}$, David T. Defining potential targets for immunotherapy in Burkholderia cepacia infection. FEMS Immunol Med Microbiol 1995; 10: 157-164.

98. Parr TR, Moore RA, Moore LV, Hancock REW. Role of porins in intrinsic antibiotic resistance of Pseudomonas cepacia. Antimicrob Agents Chemother 1987; 31; 121-123.

99. Konstan MW, Hilliard KA, Norvell TM, Berger M. Bronchoalveolar lavage findings in cystic fibrosis patients with stable, clinically mild lung disease suggest ongoing infection and inflammation. Am $J$ Respir Crit Care Med 1994; 150: $448-454$

100. Döring G. The role of neutrophil elastase in chronic inflammation. Am J Respir Crit Care Med 1994; 150: S114-S117.

101. Suter S. The role of bacterial proteases in the pathogenesis of cystic fibrosis. Am J Respir Crit Care Med 1994; 150: S118-$\mathrm{S} 122$.

102. Elborn JS, Dodd M, Maddison J et al. Clinical and inflammatory responses in CF patients infected with Pseudomonas aeruginosa and Pseudomonas cepacia. Pediatr Pulmonol 1994; 10 Suppl: 287.

103. Shaw D. The regulation and biological activity of cell surface determinants in model opportunist aerobic and anaerobic bacterial pathogens. PhD thesis, University of Edinburgh: 1995.

104. Shaw D, Poxton IR, Govan JRW. Biological activity of Burkholderia (Pseudomonas) cepacia lipopolysaccharide. FEMS Immunol Med Microbiol 1995; 11: 99-106.

105. Shaw D, Poxton IR, Govan JRW. The induction of TNF by 
B. cepacia and $P$. aeruginosa lipopolysaccharide. 20th European Cystic Fibrosis Conference, Brussels 1995: O9.

106. Kiska DL, Kerr A, Jones MC et al. Accuracy of four commercial systems for identification of Burkholderia cepacia and other Gram-negative nonfermenting bacilli recovered from patients with cystic fibrosis. J Clin Microbiol 1996; 34: $886-891$.

107. Leff LG, Kernan RM, McArthur JV, Shimkets LJ. Identification of aquatic Burkholderia (Pseudomonas) cepacia by hybridization with species-specific rRNA gene probes. Appl Environ Microbiol 1995; 61: 1634-1636.

108. Vandamme P. Emerging new "Pseudomonas" species in cystic fibrosis. 20th European Cystic Fibrosis Conference, Brussels 1995: L1.

109. Ursing JB, Rosello-Mora RA, Garcia-Valdes E, Lalucat J. A pragmatic approach to the nomenclature of phenotypically similar genomic groups. Int J Syst Bacteriol 1995; 45: 604.

110. Stableforth DE, Smith DL. Pseudomonas cepacia in cystic fibrosis. Thorax 1994; 49: 629-630.

111. Govan JRW. Burkholderia cepacia in cystic fibrosis. $N$ Engl J Med 1995; 332: 819-820.

112. LiPuma JJ, Stull TL. Burkholderia cepacia in cystic fibrosis. $N$ Engl J Med 1995; 332: 820.

113. Butler SL, Nelson JW, Govan JRW. Cell surface characteristics of Pseudomonas cepacia isolates from patients with cystic fibrosis. XI International CF Congress, Dublin 1992. Abstract TP8.

114. Sajjan US, Forstner JF. Identification of the mucin-binding adhesin of Pseudomonas cepacia isolated from patients with cystic fibrosis. Infect Immun 1992; 60: 1434-1440.

115. Sajjan US, Sun L, Goldstein R, Forstner JF. Cable (cbl) type II pili of cystic fibrosis-associated Burkholderia (Pseudomonas) cepacia: nucleotide sequence of the $c b l A$ major subunit pilin gene and novel morphology of the assembled appendage fibers. J Bacteriol 1995; 177: 1030-1038.

116. Sylvester FA, Sajjan US, Forstner JF. Burkholderia (basonym Pseudomonas) cepacia binding to lipid receptors. Infect Immun 1996; 64: 1420-1425.

117. Nelson JW, Doherty CJ, Brown PH, Greening AP, Kaufmann ME, Govan JRW. Pseudomonas cepacia in inpatients with cystic fibrosis. Lancet 1991; 338: 1525.

118. Burdge DR, Nakielna EM, Noble MA. Case-control and vector studies of nosocomial acquisition of Pseudomonas cepacia in adult patients with cystic fibrosis. Infect Control Hosp Epidemiol 1993; 14: 127-130.

119. Hutchinson GR, Parker S, Pryor JA et al. Home-use nebulizers: a potential primary source of Burkholderia cepacia and other colistin-resistant, Gram-negative bacteria in patients with cystic fibrosis. J Clin Microbiol 1996; 34: $584-587$.

120. Takigawa K, Fujita J, Negayama K et al. Nosocomial outbreak of Pseudomonas cepacia respiratory infection in immunocompromised patients associated with contaminated nebulizer devices. Kansenshogaku Zasshi 1993; 67: 11151125.

121. Humphreys H, Peckham D, Patel P, Knox A. Airborne dissemination of Burkholderia (Pseudomonas) cepacia from adult patients with cystic fibrosis. Thorax 1994; 49: 11571159.

122. Homma Y, Sato Z, Hirayama F, Kanno K, Shirahama H Suzui T. Production of antibiotics by Pseudomonas cepacia as an agent for biological control of soilborn plant pathogens. Soil Biol Biochem 1989; 21: 723-728.

123. Fridlander $M$, Inbar J, Chet I. Biological control of soilborne plant pathogens by a $\beta$-1,3-glucanase-producing Pseudomonas cepacia. Soil Biol Biochem 1993; 25: 1211-1222.

124. Bhat MA, Tsuda M, Horike K, Nozaki M, Vaidyanathan CS, Nakazawa $T$. Identification and characterization of a new plasmid carrying genes for degradation of 2,4-dichlorophenoxyacetate from Pseudomonas cepacia CSV90. Appl Environ Microbiol 1994; 60: 307-312.
125. Havel J, Reineke W. Degradation of Aroclor 1221 in soil by a hybrid pseudomonad. FEMS Microbiol Lett 1993; 108: $211-217$

126. Krumme ML, Timmis KN, Dwyer DF. Degradation of trichloroethylene by Pseudomonas cepacia G4 and the constitutive mutant strain G4 5223 PR1 in aquifer microcosms. Appl Environ Microbiol 1993; 59: 27462749.

127. Anonymous. Less beef, more brains. Lancet 1996; 347: 915.

128. Taplin D, Bassett DCJ, Mertz PM. Foot lesions associated with Pseudomonas cepacia. Lancet 1971; 2: 568-571.

129. Smith JJ, Travis SM, Greenberg EP, Welsh MJ. Cystic fibrosis airway epithelia fail to kill bacteria because of abnormal airway surface fluid. Cell 1996; 85: 229-236.

\section{Note added in proof}

Following submission of this review, the results of an epidemiological study of $B$. cepecia in a large series of $\mathrm{CF}$ patients attending the $\mathrm{CF}$ centre in Verona were published. Cazzola et al. concluded that their results are difficult to interpret. Nevertheless, data are essential if progress is to be made in unravelling $B$. cepacia epidemiology, and the results of this study are particularly relevant to the major issues discussed in our review.

Between Nov. 1991 and Dec. 1994, B. cepacia was cultured from $85(11.0 \%)$ of $769 \mathrm{CF}$ patients attending the Verona centre. Based on genomic fingerprinting, $32(53.3 \%)$ patients were colonised by individual $B$. cepacia strains; the remaining $28(46.7 \%)$ patients were divided into 10 subgroups, each colonised by a distinct strain. As previously encountered with the ET12 lineage, the outcome of B. cepacia colonisation in the Verona study varied from rapidly fatal septicaemia to maintenance of reasonably stable respiratory function, even in patients colonised by the same strain. Cazzola et al. provide further evidence for hypotheses discussed in our review that some $B$. cepacia strains exhibit and low transmissibility that the environment is a likely source of sporadic new cases: e.g., transmission was observed in only three of eight pairs of CF siblings; in unrelated patients, direct person-to-person transmission was evident in only 10 cases (16.7\%); despite a strict segregation policy, whether as in- or out-patients, 15 new colonised patients were identified during 1993. Considering social implications and the paucity of previous data, it was particularly interesting to note that transmission was demonstrated between two unrelated $\mathrm{CF}$ schoolmates.

Cazzola G, Amalfitano G, Tonelli E, Perazzoli C, Piacentini I, Mastella G. Burkholderia (Pseudomonas) cepacia epidemiology in a cystic fibrosis population: a genome finger-printing study. Acta Paediatr 1996; 85: 554-557. 